\title{
Erratum to: A comparison of coronary CTA and stress testing using high-efficiency SPECT MPI for the evaluation of chest pain in the emergency department
}

\author{
W. Lane Duvall, MD, ${ }^{a}$ John A. Savino, MD, ${ }^{b}$ Elliot J. Levine, $M D,{ }^{b}$ \\ Usman Baber, $M D,{ }^{a}$ Jonathan T. Lin, $M D,{ }^{b}$ Andrew J. Einstein, $M D, P h D,{ }^{c}$ \\ Luke K. Hermann, $M D{ }^{d}$ and Milena J. Henzlova, $M^{a}$ \\ a Mount Sinai Division of Cardiology (Mount Sinai Heart), Mount Sinai Medical Center, New York, \\ NY \\ b Mount Sinai Department of Medicine, Mount Sinai Medical Center, New York, NY \\ c Division of Cardiology, Department of Medicine, and Department of Radiology, Columbia \\ University Medical Center, New York, NY \\ d Mount Sinai Department of Emergency Medicine, Mount Sinai Medical Center, New York, NY
}

Received Feb 3, 2014; accepted Feb 3, 2014

doi: $10.1007 / \mathrm{s} 12350-014-9868-6$

\section{ERRATUM TO: J NUCL CARDIOL \\ DOI 10.1007/S12350-013-9823-Y}

We would like to withdraw Dr Javier Sanz from the list of authors on the manuscript entitled "A Comparison of Coronary CTA and Stress Testing Using HighEfficiency SPECT MPI for the Evaluation of Chest Pain in the Emergency Department', per his request. Instead the authors would like to acknowledge and thank him for his contributions to the project including his thoughtful editing and revisions to the manuscript.

The online version of the original article can be found under doi:10.1007/s12350-013-9823-y.

Reprint requests: W. Lane Duvall, MD, Mount Sinai Division of Cardiology (Mount Sinai Heart), Mount Sinai Medical Center, One

Gustave L Levy Place, Box 1030, New York, NY 10029; william. duvall@msnyuhealth.org.

J Nucl Cardiol 2014;21:660.

$1071-3581 / \$ 34.00$

Copyright (c) 2014 American Society of Nuclear Cardiology. 